


\begin{tabular}{|c|c|c|}
\hline $\begin{array}{l}\text { ISSN 2525-4812 (versão online) } \\
\text { ISSN 2238-7641 (versão impressa) } \\
\text { http://www.revistaterceiramargem.com/ } \\
\text { index.php/terceiramargem/index }\end{array}$ & $\begin{array}{c}\text { Recebido em: 30/8/2019 } \\
\text { Aprovado em: 12/2/2020 } \\
\text { Período de publicação: jan./jun., } 2020\end{array}$ & $\begin{array}{c}\text { Revista Terceira } \\
\text { Margem Amazônia } \\
(\text { v. } 6 \cdot \mathrm{n} .14 \cdot \mathrm{Jan} . / \mathrm{Jun} .2020)\end{array}$ \\
\hline
\end{tabular}

Como citar o artigo:

OLIVEIRA, K. R. A; BERNARDES, C.; BERNARDES, R. S. Tecnologias sociais de acesso à água em comunidades extrativistas: um longo processo para garantia de um direito humano. Revista Terceira Margem Amazônia, v. 6, n. 14, p. 63-78, 2020. DOI: http://dx.doi.org/10.36882/2525-4812.2020v6i14p63-78

\title{
TECNOLOGIAS SOCIAIS DE ACESSO À ÁGUA EM COMUNIDADES EXTRATIVISTAS: UM LONGO PROCESSO PARA GARANTIA DE UM DIREITO HUMANO
}

\author{
Karla Rosane Aguiar Oliveira ${ }^{1}$ \\ Carolina Bernardes ${ }^{2}$ \\ Ricardo Silveira Bernardes ${ }^{3}$
}

\begin{abstract}
Resumo: O acesso a água e saneamento, estabelecido como direito humano desde 2010, ainda se constitui como desafio a populações em situação de vulnerabilidade social. Na Amazônia, há uma dívida sanitária histórica do Estado brasileiro para as comunidades extrativistas. A partir de 2007, uma iniciativa motivada por moradores da Reserva Extrativista do Médio Juruá, no município de Carauari, estado do Amazonas, possibilitou a elaboração e construção de tecnologias sociais de acesso à água e ao saneamento, mudando a realidade local. Por meio de um processo participativo, a tecnologia se tornou política pública a partir de 2014. Este artigo busca analisar, por meio do relato histórico, como se deu esse processo, que atualmente garante qualidade de vida e bem-estar a populações tradicionais em toda a Amazônia.
\end{abstract}

Palavras-chave: Amazônia, acesso à água, saneamento, populações tradicionais.

\section{SOCIAL TECHNOLOGIES OF ACCESS TO WATER IN EXTRACTIVE COMMUNITIES: A LONG PROCESS TO GUARANTEE A HUMAN RIGHT}

\begin{abstract}
Water and sanitation access were established as human right since 2010, but still remains as a challenge to socially vulnerable populations. In the Amazon, there is a historical sanitary doubt from the Brazilian state to traditional populations. Since 2007, by an initiative that came from 'Médio Juruá Extractive Reserve' residents in Carauari (municipality in Amazonas' State), a water and sanitation social technology was elaborated and constructed by traditional communities, and it has changed the local reality. It also has become public policy by a participatory process since 2014 . Through a historical report, this paper aims to analyze how this process could provide life quality and well-being to traditional communities all over the Amazon.
\end{abstract}

Key words: Amazon, water access, sanitation, traditional populations.

\footnotetext{
${ }^{1}$ Engenheira florestal, consultora técnica nas áreas de povos e comunidades tradicionais, tecnologias sociais de acesso à água. E-mail: karla.oliveiradf@gmail.com

${ }^{2}$ Bióloga, consultora técnica independente. E-mail: carolina1601@yahoo.com

${ }^{3}$ Engenheiro civil, professor associado da Universidade de Brasília. E-mail: rsilveirabernardes@gmail.com
} 


\section{Introdução}

O acesso ao abastecimento de água seguro e economicamente viável e confiável (contínuo e com qualidade sanitária) é um dos fatores essenciais para o desenvolvimento social. Em julho de 2010 foi aprovada a Resolução nº 64/292 da Assembleia Geral da Organização das Nações Unidas (ONU), que reconhece formalmente o direito ao abastecimento de água e ao esgotamento sanitário como essencial à concretização de todos os direitos humanos, incluindo o direito humano à alimentação adequada.

Porém, de acordo com a Organização Mundial de Saúde (OMS), em 2017, havia 2,1 bilhões de pessoas utilizando fontes de água inseguras ou contaminadas no planeta. Ou seja, uma em cada três pessoas conta com água imprópria, que provoca doenças. Além disso, $20 \%$ da população mundial possui formas inapropriadas de esgotamento sanitário, dos quais quase 1 bilhão de pessoas realizam suas necessidades a céu aberto, principalmente em áreas rurais (WORLD HEALTH ORGANIZATION; UNICEF, 2017).

As crianças são as mais afetadas por doenças de origem ambiental e por veiculação hídrica. O relatório da OMS intitulado Não Polua Meu Futuro informa que em 2015 foram registradas 361 mil mortes de crianças em virtude de doenças diarreicas decorrentes da falta de acesso a água potável, saneamento e higiene. Cerca de $26 \%$ de todas as mortes registradas poderiam ser prevenidas com medidas simples, como lavar as mãos, tomar banho e não realizar a defecação a céu aberto (WORLD HEALTH ORGANIZATION, 2017).

O saneamento é entendido, neste trabalho, em uma perspectiva global, que compreende acesso a água, esgotamento sanitário e hábitos adequados de higiene. A definição do primeiro termo (acesso à água) pode ser usada com variações conceituais, as quais incorporam diferenças sociais, econômicas e políticas em relação a variáveis de qualidade, quantidade, disponibilidade e regularidade à água (HOWARD; BARTRAM, 2003). Os benefícios proporcionados pelos investimentos em saneamento (água, esgotamento sanitário e práticas de higiene) estão relacionados à redução da transmissão de doenças infecciosas. Porém, a principal motivação dos usuários de sistemas de saneamento tem relação com aspectos que incluem o desejo por privacidade e conforto (JENKINS; SCOTT, 2007).

A fonte de água meteórica, água da chuva, pode ser considerada como fonte segura de disponibilidade do recurso (WORLD HEALTH ORGANIZATION, 2019). A ocorrência e disponibilidade de chuva de forma gratuita, mesmo que não abundante em todas as regiões do planeta, podem proporcionar a garantia do direito humano à água de qualidade e ao saneamento de populações mais vulneráveis.

No caso da Amazônia Brasileira, conforme relatado por Bernardes (2013), o acesso à água em comunidades rurais se dá, em geral, por cacimbas ou pelo curso dos rios. Geralmente estão contaminadas em virtude da proximidade com áreas do esgotamento sanitário das comunidades rurais, também de poluentes lançados por embarcações, etc. O tratamento realizado pelos seus residentes não necessariamente elimina os agentes patógenos da água, provocando uma miríade de doenças de veiculação hídrica. Uma das alternativas seria o uso de água de chuva como fonte para consumo, considerando sua disponibilidade relativamente abundante na região. 
A questão dos recursos hídricos para consumo humano na Amazônia perpassa necessariamente por modelos de tecnologias que diminuam a incidência de esgoto lançado nos cursos d'água (esgotamento sanitário), por fontes potáveis, como a água das chuvas, e por hábitos adequados de higiene no domicílio e peridomicílio das comunidades rurais.

Desde 2007 diversos atores, entre pesquisadores, comunidades tradicionais e representantes governamentais, desenvolvem de forma participativa, por meio de articulações em assembleias e reuniões, a implementação de tecnologia social (TS) para acesso a água e esgotamento sanitário em comunidades rurais na Amazônia.

O presente artigo busca, portanto, analisar como se deu o processo construtivo das tecnologias sociais de acesso à água na Amazônia sob o enfoque do direito humano à alimentação adequada. A metodologia utilizada no presente trabalho dar-se-á pelo relato da experiência e pela análise do processo ocorrido no município de Carauari, estado do Amazonas, desde a implantação das primeiras tecnologias no ano de 2006 até tornar-se política pública, a partir de 2014 .

O artigo está dividido da seguinte forma: no primeiro tópico realizou-se uma reflexão sobre o direito a água e saneamento e o papel das tecnologias sociais para a inclusão social de populações em vulnerabilidade, em especial as comunidades extrativistas da Amazônia. Depois foi descrito como se deu propriamente o processo participativo de criação e construção dos sistemas pluvial multiuso comunitário e autônomo na Reserva Extrativista (Resex) do Médio Juruá, no estado do Amazonas. Por fim, discute-se como essas tecnologias ganharam escala ao se tornarem política pública para a promoção do direito a água e saneamento.

\section{O Direito à Água e ao Saneamento e Tecnologias Sociais: A Promoção da Inclusão Social para Populações Extrativistas da Amazônia}

O direito a água e saneamento só foi considerado efetivamente um direito humano seis décadas após a Declaração Universal de Direitos Humanos, publicada pela ONU em 1948. Tal direito foi reconhecido por meio da Resolução 64/292 em julho de 2010, com o seguinte texto: “...o direito à água potável e limpa, e o direito ao saneamento como direito humano que é essencial para o pleno gozo da vida e de todos os direitos humanos" (ONU, 2010). O fato de o Estado brasileiro ter ratificado os tratados e acordos internacionais sobre o direito humano à água e ao saneamento significa que ele assume esse conjunto de obrigações.

O processo de identificação das desigualdades sociais e a falta de acesso ao direito à água está diretamente relacionado a um processo histórico de dívida sanitária, conforme abordado por Castellanos (1990). Uma das consequências dessa dívida é a degradação das condições de vida da população.

Novos desafios globais também se impõem nessa realidade. As mudanças climáticas geradas em decorrência da atividade humana ao longo dos últimos tempos já impactam a saúde pública e a segurança alimentar de diversas populações no planeta. Nas regiões de maior escassez hídrica, as mudanças climáticas vêm causando migrações forçadas de um grande contingente de pessoas que depende da água para sua sobrevivência (PROGRAMA DAS NAÇÕES UNIDAS PARA O DESENVOLVIMENTO, 2019). 
Padrões sobre qualidade da água para consumo humano são bem definidos internacionalmente por diretrizes da OMS (WORLD HEALTH ORGANIZATION, 2004) e, no Brasil, pela Portaria $n^{\circ}$ 2.914/2011 do Ministério da Saúde (BRASIL, 2011). Mas as diretrizes sobre a quantidade adequada de água que se configure em benefícios para a saúde humana e o bem-estar, considerando diferentes níveis de consumo, estão sistematizadas somente na literatura especializada (CAIRNCROSS; FEACHEM, 1993; ESREY et al., 1991; HOWARD; BARTRAM, 2003).

A definição de acesso à água pode ser usada com variações conceituais, as quais incorporam diferenças sociais, econômicas e políticas em relação a variáveis de qualidade, quantidade, disponibilidade e regularidade de acesso (HOWARD; BARTRAM, 2003; IBGE, 2008).

De acordo com Howard e Bartram (2003), a distância percorrida e o tempo gasto para a obtenção de água para consumo são fatores determinantes na definição de seu acesso. Estes refletem, em última instância, os efeitos sobre a saúde e qualidade de vida do usuário, conforme apresentado na Tabela 1.

Tabela 1. Níveis de acesso à água e relação com a promoção de saúde.

\begin{tabular}{|c|c|c|c|}
\hline Nível de acesso & Medidas de acesso & Demanda atendida & $\begin{array}{c}\text { Grau de efeito } \\
\text { negativo à saúde }\end{array}$ \\
\hline $\begin{array}{c}\text { Sem acesso } \\
(<5 \mathrm{~L} / \text { pessoa/dia })\end{array}$ & $\begin{array}{l}\text { Mais de } 1.000 \mathrm{~m} \text { e/ou } 30 \\
\text { minutos de tempo para } \\
\text { coleta }\end{array}$ & $\begin{array}{l}\text { Consumo - Não assegurado } \\
\text { Higiene - Não é possível (somente } \\
\text { na fonte) }\end{array}$ & Muito alto \\
\hline $\begin{array}{c}\text { Acesso básico } \\
\text { (média } 20 \mathrm{~L} / \text { pessoa/dia) }\end{array}$ & $\begin{array}{l}\text { Entre } 100 \text { e } 1.000 \mathrm{~m} \text { e/ou } \\
\text { 5-30 minutos de tempo para } \\
\text { coleta }\end{array}$ & $\begin{array}{l}\text { Consumo - Assegurado } \\
\text { Higiene básica e de alimentos } \\
\text { possível } \\
\text { Dificuldade para garantir lavagem } \\
\text { de roupa, louça e banho }\end{array}$ & Alto \\
\hline $\begin{array}{c}\text { Acesso intermediário } \\
\text { (média de } 50 \mathrm{~L} / \text { pessoa/ } \\
\text { dia) }\end{array}$ & $\begin{array}{l}\text { Água fornecida por torneira } \\
\text { pública (ou à distância de } \\
100 \text { m ou } 5 \text { minutos de } \\
\text { tempo para coleta) }\end{array}$ & $\begin{array}{l}\text { Consumo - Assegurado } \\
\text { Higiene básica e de alimentos } \\
\text { assegurada, assim como banho e } \\
\text { lavagem de roupa e louça }\end{array}$ & Baixo \\
\hline $\begin{array}{l}\text { Acesso ótimo }(\geq 100 \mathrm{~L} / \\
\text { pessoa/dia })\end{array}$ & $\begin{array}{l}\text { Água fornecida por } \\
\text { múltiplas torneiras, } \\
\text { continuamente }\end{array}$ & $\begin{array}{l}\text { Todas as necessidades de consumo } \\
\text { e higiene são asseguradas }\end{array}$ & Muito baixo \\
\hline
\end{tabular}

Fonte: Howard e Bartram (2003).

Segundo Cairncross e Feachem (1993), a quantidade de água utilizada pela população decresce significativamente (de 50 litros para valores menores que 10 litros por pessoa/dia) quando o tempo para obter a água excede 5 minutos ou 100 metros de distância. Assim é desejável que o acesso esteja dentro desses parâmetros para a população usuária.

No Brasil, em 2002, metade das pessoas que se encontravam em situação de pobreza extrema não tinham acesso à água potável. Além disso, 76\% não tinham acesso a esgotamento sanitário. Deste modo, ao olhar para a parcela mais pobre da população brasileira, a falta de água potável e de saneamento básico agravava os problemas decorrentes das doenças perpetuadoras da pobreza, tais como verminoses, diarreias, e a mortalidade infantil (CAMPELLO, 2017). 
Diversos personagens importantes da nossa história já assinalavam que, na Amazônia, a falta de saneamento básico gera uma "patologia anarquizada". Por ocasião das campanhas de saúde na região Amazônica feitas por Oswaldo Cruz e Carlos Chagas em 1913, diagnósticos precisos foram efetuados sobre o problema. Na publicação de O Problema Sanitário da Amazônia (1917), de autoria de Afrânio Peixoto, foi constatado que:

"Para todas (as doenças citadas) o remédio é sabido, de prevenção e cura, mas falta a educação do povo e médicos numerosos e idôneos, capazes de corrigirem, senão de obrigarem, tantos males. [...] o uso da água fervida, sempre que for suspeita a de bebida; o uso de calçado; a defecação em lugares onde as larvas dos vermes não se disseminem para as infestações [...]" (BATISTA, 1972, p. 189).

Ou seja, há uma dívida histórica do Brasil em relação às questões de saneamento das populações extrativistas da Amazônia. De acordo com Bernardes (2013), esse cenário pouco mudou em mais de 100 anos. A taxa de parasitoses intestinais presentes nas populações ribeirinhas gira em torno de $53 \%$ a $76 \%$, valores semelhantes aos encontrados no início do século XX por Euclides da Cunha e Oswaldo Cruz. Assim, a garantia de acesso a água e saneamento é, antes de tudo, um processo de inclusão social de comunidades em pobreza e extrema pobreza rural.

Duas vertentes de atuação têm sido adotadas para o desenvolvimento de ações de saneamento em comunidades rurais da Amazônia: a primeira sustenta-se na ação de políticas públicas desenvolvidas em formatos verticais, em que os projetos e a implementação em si se dão por meio de ações sem a participação dos beneficiários. A segunda baseia-se em ações e políticas públicas construídas de forma horizontal, de forma participativa, visando melhorar a qualidade de vida da população. É nesse sentido que o conceito de tecnologia social (TS) pode apoiar a reflexão crítica sobre acesso à água e ao saneamento na Amazônia.

A característica participativa dessa vertente envolve, no processo de implementação da tecnologia, etapas de mobilização social e capacitação com a participação de atores sociais associados à implementação da tecnologia e os beneficiários dela.

Considerando essas características, a TS busca ser adaptada a um tamanho pequeno, para abranger todos os indivíduos; é liberadora do potencial criativo, físico e financeiro de seu produtor; não é discriminatória entre patrão/chefe e empregados; ela é capaz de viabilizar economicamente os empreendimentos autogestionados e as pequenas empresas; e é orientada ao mercado interno (DAGNINO, 2014, p. 23). Assim, a TS se diferencia não por somente ter sido criada sob o vulto da inovação social ou porque possui baixo custo, mas em especial porque tem valores e características que visam à reprodução para a inclusão social e redução da pobreza.

As TS estão relativamente disseminadas em várias áreas e interagem como soluções sustentáveis e inovadoras de baixo custo, simples e de dimensão local. Mas, para serem aptas a objetos de políticas públicas, devem congregar alguns procedimentos e técnicas, a saber (adaptado de LASSANCE JUNIOR; PEDREIRA, 2004):

(i) A partir da TS é possível articular uma ampla rede de atores sociais. 
(ii) Possuir um padrão tecnológico básico com modelos flexíveis, ou seja, possibilitar adaptações inteligentes e espírito inovador (e não a simples replicação dela).

(iii) Cumprir os quatro critérios para sua viabilidade em escala, ou seja, fase de criação, a partir da sabedoria popular; consolidação do modelo tecnológico (projeto básico e roteiro de construção); viabilidade política, por meio da reivindicação da sociedade civil e movimentos sociais para sua implantação; e a viabilidade social, a partir do ganho de escala.

(iv) Essas fases, se plenamente cumpridas, possibilitam a articulação entre governos e organizações sociais.

A questão da água na Amazônia perpassa necessariamente por modelos de TS que diminuam a incidência de esgoto lançado nos cursos d'água e por fontes de água potável, como se verá a seguir.

\section{Sobre a Experiência de Implantação das TS de Acesso à Água na Amazônia}

As populações extrativistas da Amazônia conhecem bem os problemas decorrentes da ausência de acesso a saneamento e equipamentos públicos de saúde. Há uma demanda histórica nesse sentido, e as comunidades extrativistas do Rio Juruá, no estado do Amazonas, foram buscar soluções para o problema.

A demanda por acesso a água para consumo humano e saneamento foi apresentada pela população extrativista no ano de 2006 dentro das atividades de assembleias e conselho deliberativo da Reserva Extrativista (Resex) do Médio Juruá. Iniciou-se uma articulação entre sociedade civil, associações comunitárias, poder público, prefeitura e órgãos gestores das unidades e profissionais de universidades, a fim de construir tecnologias sociais de acesso à água que considerassem de forma interligada questões técnicas, sociais e ambientais.

Nas discussões foram realizados debates e reuniões com um conjunto de diversos atores. Esse processo demorou cerca de um ano, de 2006 a 2007. Nesse período ficou claro que as soluções tecnológicas de acesso a água não deveriam contemplar unicamente o ponto de uso de água em qualquer local dentro dos domicílios. Para as populações envolvidas, a proposta de TS deveria contemplar pontos de usos anexados ao domicílio que viabilizassem a privacidade dos usuários, nos termos indicados por Jenkins e Scott (2007).

De acordo com o diagnóstico realizado à época, as variáveis demandadas pelas comunidades estavam em conformidade com o nível de acesso ótimo à água (menos de 5 metros de distância da residência), associado a um alto benefício à saúde das populações atendidas, como apresentado por Howard e Bartram (2003).

A TS inicialmente implementada no projeto piloto continha um módulo familiar com um componente para captação de água de chuva do telhado, dispositivo de tratamento, um reservatório individual elevado com capacidade de 1.000 litros, uma instalação sanitária domiciliar e a instalação de quatro pontos de uso, inclusive vaso sanitário e fossa simplificada. 
O módulo complementar era composto por captação de água de fonte complementar, tratamento simplificado, reservatório comunitário de 5 mil litros e rede de distribuição de água aos módulos familiares. Esse sistema, de caráter comunitário, possuía uma unidade de tratamento e reservação de água e uma rede de distribuição de água por gravidade. Essa tecnologia foi projetada para atender cerca de dez famílias.

Além dos componentes construtivos da TS, a implementação dessa tecnologia contou com etapas participativas de mobilização social e capacitação. A mobilização consistiu na realização de assembleias com o público-alvo e reuniões com as famílias para entendimento da proposta. Esse foi o primeiro momento formativo, em que as pessoas foram esclarecidas sobre a tecnologia que ali chegava e de como seriam as demais etapas de execução.

Ademais, ao longo da sua execução, o projeto piloto contou com um processo de capacitação técnica e de gestão dos envolvidos na construção (pedreiros) e outro em saúde ambiental para toda a comunidade. A capacitação teve como finalidade apoiar os processos de organização comunitária para manutenção dos componentes da tecnologia. Mas não só: buscou também orientar as pessoas em relação a aspectos relacionados à saúde e higiene pessoal, o que se verifica como fundamental para o sucesso da proposta de saneamento (OLIVEIRA; BERNARDES, 2019).

Com apoio financeiro da Petrobrás, o Projeto Sanear iniciou em 2007. A Associação de Produtores Rurais de Carauari (Asproc) foi a proponente em parceria com a Universidade de Brasília (UnB), que ofereceu apoio para elaboração do projeto técnico. Foram, então, implementadas 145 tecnologias sociais, que se encontram até o presente momento em pleno funcionamento.

Os diálogos realizados com as comunidades extrativistas de outras reservas extrativistas eram de que os representantes dessas populações ampliassem a oferta da TS nas demais regiões da Amazônia. Porém, diversos ajustes à tecnologia foram necessários antes de ampliar a proposta em âmbito nacional. Abaixo, estão algumas das principais modificações técnicas realizadas ao longo do tempo.

\section{Materiais escolhidos para construção das TS}

A proposta de tecnologia social implementada no Projeto Sanear tinha, entre seus componentes construtivos, uma pia de cozinha e uma instalação sanitária domiciliar (banheiro e fossa simplificada), pia e chuveiro para cada unidade domiciliar; além disso, havia um reservatório para armazenamento de água e um sistema domiciliar de captação de água de chuva. Também contemplava um sistema coletivo de captação de água subterrânea associado a uma unidade de tratamento da água. Uma vez tratada, a água era distribuída aos reservatórios domiciliares da comunidade.

A necessidade do uso da água subterrânea foi decorrente da realidade do "verão" amazônico, quando há uma sazonal diminuição da precipitação local. O uso de poço tubular raso foi uma opção, pois havia uma pessoa em Carauari com experiência em fazer esse tipo de poço com trado manual em áreas de várzea. A solução serviu de demonstrativo da viabilidade da alternativa, uma vez que a técnica construtiva demanda uso intensivo de mão de obra e baixo requisito de equipamentos, inexistentes nas comunidades. 


\section{Placas de concreto pré-moldadas}

Quanto ao material utilizado para construção dos banheiros, destaca-se que, no projeto, cogitou-se o uso da madeira, por ser o mais utilizado nas edificações das comunidades. Entretanto, essa opção foi logo descartada, visto que se dava em local de contato frequente com a água, e isso reduziria a durabilidade da TS ao longo do tempo.

Como havia recurso financeiro no projeto para a escolha de outros materiais, optou-se pelo uso de um material mais robusto e com maior durabilidade. Além disso, ocorreu o efeito do significado social da construção em "alvenaria", como forma de mostrar o compromisso de longo prazo com a duração da TS.

O principal problema levantado foi a logística de transporte dos materiais, notadamente o tijolo e o cimento. O tijolo é um material pesado e volumoso, que necessita de cimento no local para ser assentado. Em muitas comunidades, a época de transporte de materiais ocorre no inverno, quando os rios estão cheios. Mas a construção deve ocorrer no verão, quando os índices de precipitação são menores. Muito do cimento transportado foi perdido, pois os sacos desse material tiveram que ser armazenados por cerca de quatro meses antes de serem utilizados. Mesmo diante dessa e de outras dificuldades, o projeto piloto foi concluído com sucesso em 2007, e as tecnologias ainda se encontram em pleno funcionamento após mais de dez anos de uso.

Em um segundo momento, quando houve a possibilidade de expansão do Projeto Sanear para outras comunidades no interior da Resex do Médio Juruá, necessitou-se discutir estratégias de logística em relação ao material. Tal debate, então, associou as teorias de edificação junto ao corpo técnico da UnB com as experiências dos comunitários e da Asproc. Isso resultou em uma proposta do uso de placas de concreto pré-moldadas. Estas seriam construídas no município mais próximo das comunidades, Carauari, AM, depois de prontas seriam transportadas até as comunidades beneficiadas.

Destaca-se que essas placas têm volume três vezes menor que o tijolo convencional, e a forma de transporte é mais eficiente nas embarcações (barcos) utilizadas para transporte do material. Além disso, uma placa é equivalente a cerca de 15 tijolos assentados, o que implica grande economia nas viagens para transporte do material.

As placas pré-moldadas possuem um sistema de encaixe destas e dos pilares de concreto, não necessitando de cimento no local para construção. Outro benefício do uso da placa é que, por ser mais fina, cerca de $3 \mathrm{~cm}$ de espessura, permite que o espaço interior da instalação sanitária seja mais bem aproveitado.

Outros pontos positivos associados ao uso da placa foram: i) redução no tempo de construção da instalação sanitária domiciliar, de uma semana (com os tijolos) para dois dias (com as placas); ii) o uso da placa viabilizou a solução mais adequada para o revestimento das paredes da fossa simplificada, que foi feito com o mesmo padrão de placa utilizado nos banheiros; e iii) viabilizou o aprimoramento para a fossa de várzea, pois a placa convive bem com inundação. 
Diante desse contexto, conclui-se que o ajuste no material utilizado no processo construtivo foi fundamental para dar celeridade ao processo de construção das TS e otimizar a logística de entrega e construção nas comunidades.

\section{Ajuste nos materiais hidráulicos}

Outro componente ajustado ao longo do Projeto Sanear foi a encanação do sistema hidráulico dentro da instalação sanitária domiciliar. A relação entre a altura do telhado para captação da água de chuva com o reservatório e a altura do chuveiro dentro da instalação sanitária domiciliar nem sempre permitia que houvesse em algumas casas pressão suficiente no sistema para a água armazenada no reservatório sair no chuveiro.

Entretanto era importante que todas as famílias (mesmo aquelas com dificuldades logísticas) fossem atendidas. Assim, nas casas onde a cota não permitia o funcionamento de um chuveiro foram implementadas torneiras, viabilizando o uso da cuia no banho, hábito comum nas comunidades atendidas.

\section{Unidade de tratamento: filtro lento de areia}

O filtro lento de areia foi dimensionado com o uso de manta geossintética. A escolha foi em função da facilidade de limpeza do filtro e durabilidade do material ao longo do tempo. $\mathrm{O}$ uso de tal material permitiu que o tamanho da unidade filtrante fosse adequado às caixas d'água existentes no mercado, garantindo tratamento eficaz da água consumida pela comunidade.

Os itens apresentados anteriormente foram os principais ajustes realizados ao longo do tempo durante a execução do projeto. Mas, destaca-se que outros pequenos ajustes foram realizados de acordo com as demandas das comunidades junto aos conhecimentos técnicos existentes. Após esse processo participativo de ajustes, o Projeto Sanear passou a ser discutido em âmbito federal, como será discutido a seguir.

\section{Quando Uma Ideia de Base Comunitária se Torna Uma Política Pública}

As tecnologias de acesso à água devem apoiar na diminuição da incidência de esgoto lançado nos cursos d'água (esgotamento sanitário), por fontes de água potável (acesso à água de qualidade) e pelos hábitos adequados de higiene no domicílio e peridomicílio das comunidades rurais (BERNARDES, 2013; OLIVEIRA; BERNARDES, 2019).

A ampliação do Projeto Sanear desenvolvido no município de Carauari, AM, ocorreu em 2014, a partir da articulação política do Conselho Nacional das Populações Extrativistas (CNS), o Memorial Chico Mendes (MCM, ligado ao CNS) e o então Ministério do Desenvolvimento Social e Combate à Fome (MDS), representado pelo Programa Cisternas. Iniciou-se, então, um processo de sistematização de TS para toda a Amazônia.

O Programa Cisternas é uma política pública executada pelo Governo Federal em parceria com estados, consórcios públicos e organizações da sociedade civil sem fins lucrativos. Assim, o Projeto Sanear Amazônia, criado a partir da parceria entre o MCM e o MDS, implantou mais 
de 2.800 sistemas pluviais multiuso em oito reservas extrativistas situadas nos estados do Acre, Amapá, Amazonas e Pará. Seu público beneficiário eram famílias extrativistas moradoras das áreas onde não existia sistema de abastecimento de água nem saneamento públicos.

Além disso, ao ser sistematizada dentro do Programa Cisternas do MDS, a TS incorporou critérios específicos para elegibilidade de famílias, de acordo com a priorização daquelas em extrema pobreza rural. A ênfase é no papel da mulher como beneficiária prioritária, bem como famílias com crianças, portadores de necessidades especiais e idosos.

A sistematização da TS foi realizada dentro de uma proposta na qual os custos de implementação de cada tecnologia foram compostos por valores associados a mobilização, capacitação, material para construção das tecnologias e apoio operacional para viabilizar a logística associada ao processo de implementação das tecnologias. A TS Sistema Pluvial Multiuso Comunitário em Terra Firme foi, então, normatizada em 2014 e atualizada por meio da Instrução Operacional $n^{\circ}$ 3 de 4 de julho de 2018 (BRASIL, 2018b).

Nessa tecnologia, o sistema de abastecimento de água complementar comunitário é composto de três caixas d'água, respectivamente para tratamento da água, reservação e distribuição às casas por gravidade (a água vai para a unidade de captação de água da chuva da residência). Isso é demonstrado na Figura 1.

Figura 1. Sistema comunitário de tratamento e distribuição de água.

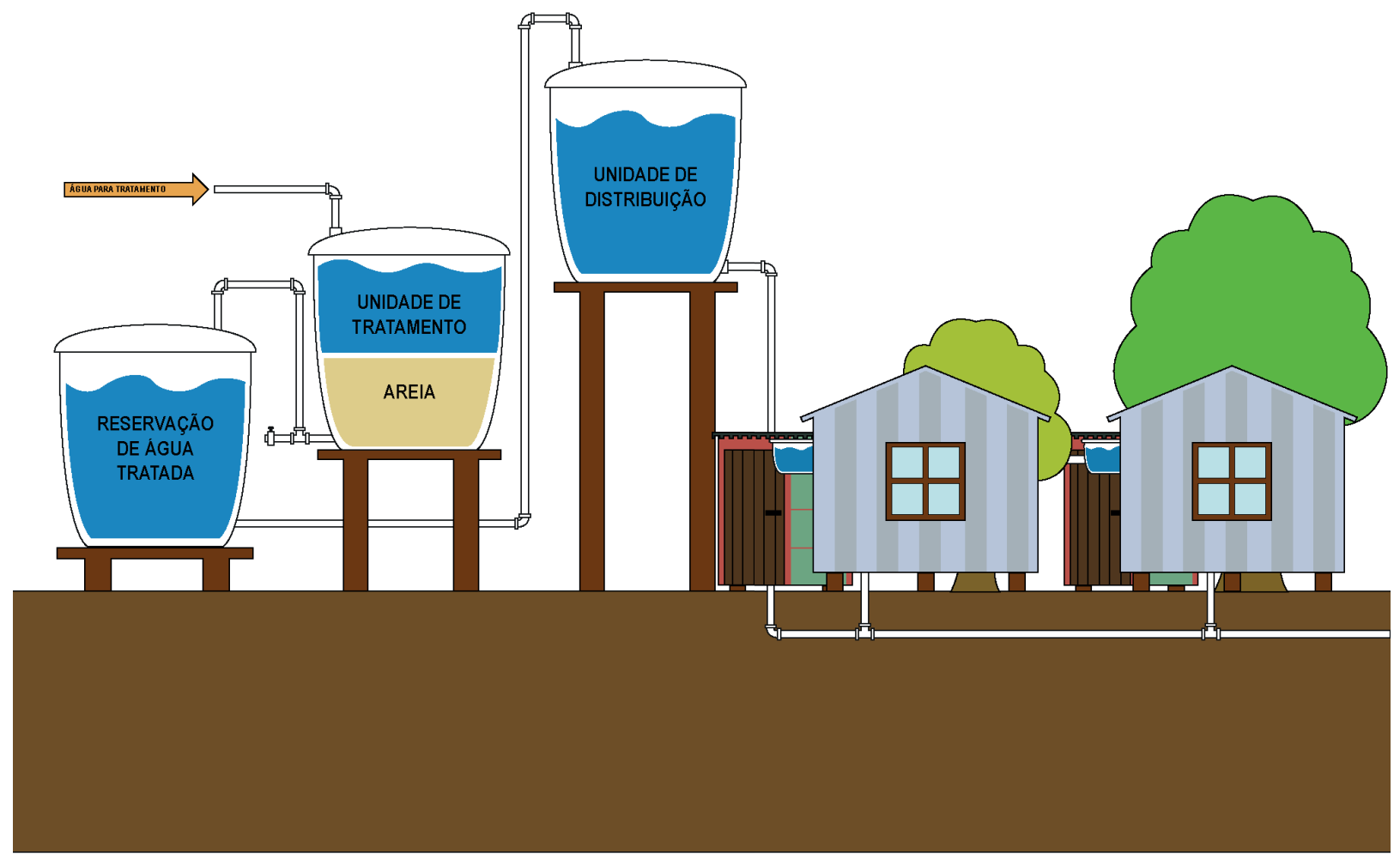

Fonte: Bernardes e Bernardes (2016, p. 28). 
A unidade de tratamento da água (primeira caixa d'água) é dimensionada considerando a água de superfície como fonte de abastecimento de água. Assim, a tecnologia também dispõe de uma estrutura de proteção flutuante que conecta a bomba elétrica e os canos que irão puxar a água do rio ou igarapé até a unidade de tratamento (Figura 2).

Figura 2. Sistema de captação da água de fonte superficial.

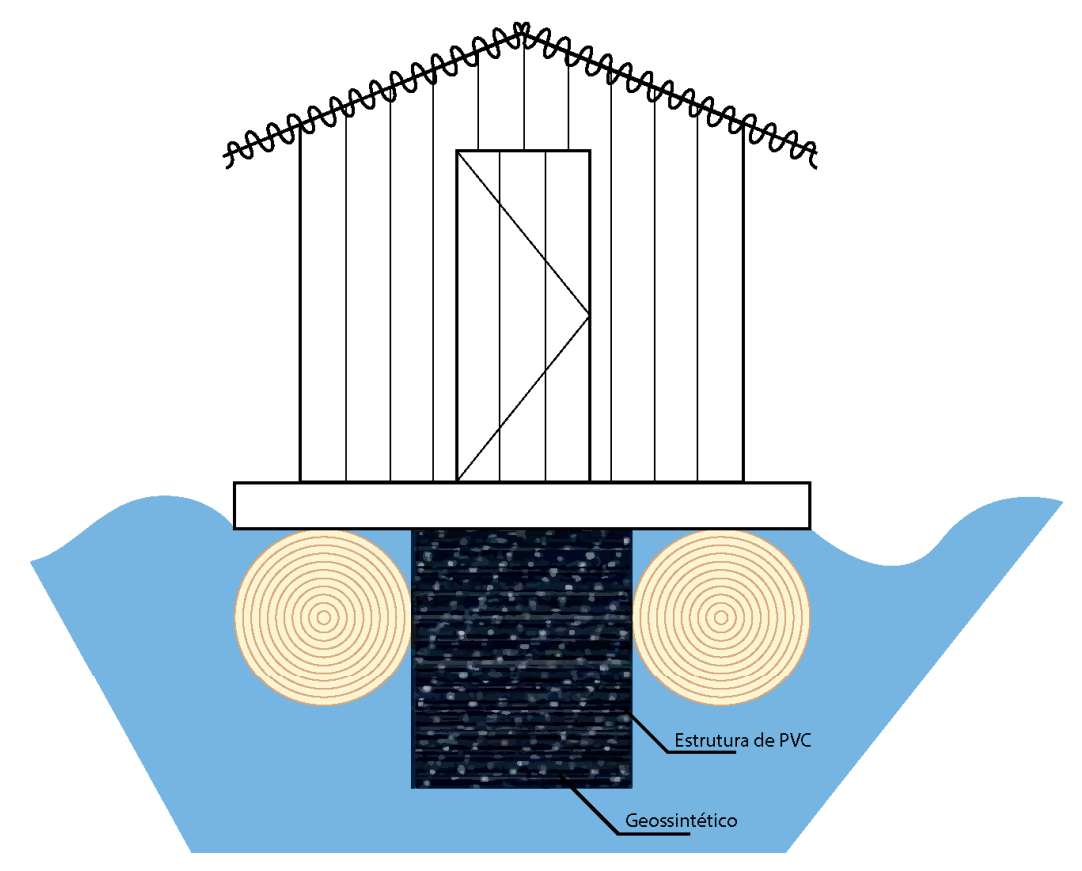

Fonte: Anexo único de Brasil (2018b, p. 21).

O sistema de tratamento de água possui uma estrutura composta por uma unidade filtrante (areia e manta geossintética), que é capaz de remover mais de 99\% dos coliformes fecais presentes na água, $100 \%$ de protozoários e ovos de helmintos, entre outros benefícios (BRASIL, 2018b).

No processo de discussão das TS no âmbito da política pública, verificou-se a necessidade de atender situações sociais e geográficas muito diferentes ao longo da região amazônica. Por exemplo, as condições e modos de vida das populações extrativistas de terra firme do Acre são essencialmente diferentes das comunidades de várzea situadas no Marajó, no Pará. Além disso, percebeu-se que, em muitas comunidades, existiam famílias que não necessariamente moravam em vilas, portanto sem acesso aos equipamentos públicos da comunidade.

Essas eram questões a serem refletidas no processo de busca por uma verdadeira inclusão social. Desta maneira, as principais alterações realizadas nas tecnologias durante o processo de ampliação estão relatadas a seguir. 


\section{Sobre o Sistema Pluvial Multiuso Autônomo}

A expansão do projeto foi dimensionada tendo como exemplo o sistema coletivo implementado no Projeto Piloto Sanear. Entretanto ficou evidente que alguns beneficiários não moravam em aglomerados comunitários. Em alguns casos, as famílias beneficiadas viviam isoladas ou em aglomerados de dois a três domicílios.

A proposta dessa nova TS foi, então, denominada de Sistema Pluvial Multiuso Autônomo. O dimensionamento da tecnologia considerou aspectos técnicos, sociais e ambientais. Foi, então, normatizada no âmbito do Programa Cisterna em 2014 e atualizada por meio da Instrução Operacional SESAN no 2 de 4 de julho de 2018 (BRASIL, 2018a).

O Sistema Pluvial Multiuso Autônomo (em terra firme) consiste em dois reservatórios (um de 1.000 litros e outro de 5.000 litros) conectados a uma estrutura de captação de água do telhado da casa (calhas e canos), que leva água para quatro pontos de água e uma fossa simplificada. Além disso, a tecnologia dispõe de um filtro de barro para tratamento da água para consumo humano. A Figura 3 busca esquematizar o modelo da TS.

Figura 3. Esquema da captação de água da chuva no telhado da moradia em um sistema pluvial multiuso autônomo.

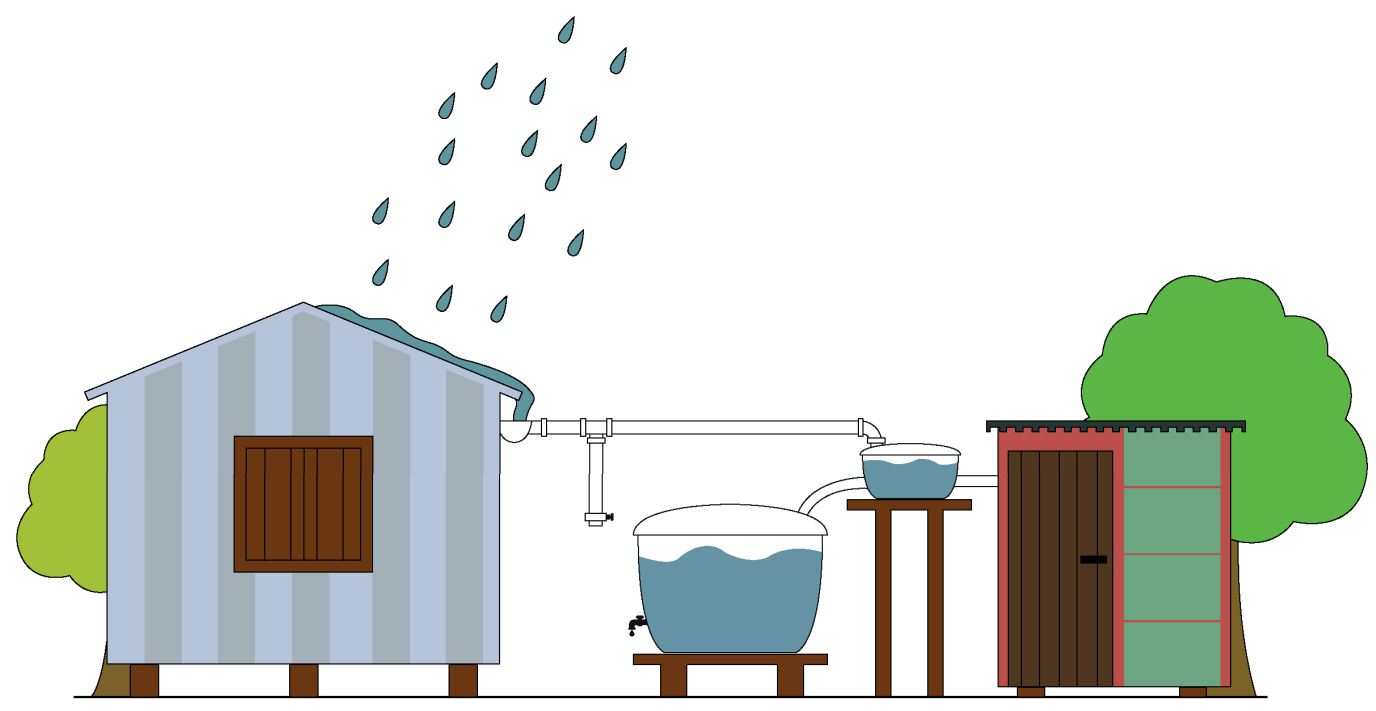

Fonte: Bernardes e Bernardes (2016, p. 27).

\section{Adaptações das TS para ambiente de várzea}

Para viabilizar a construção das TS comunitária e autônoma já sistematizadas em ambiente de várzea, três modificações foram necessárias: i) proteção para o poço durante o período de enchente; ii) elevação da cota de chegada do esgoto na fossa e consequentemente elevação da fossa; iii) elevação do piso da instalação sanitária domiciliar, para que o esgoto do vaso sanitário vá para a fossa por gravidade. 
A escavação do poço deve ser realizada nos meses de verão. Entretanto, para evitar o soterramento da fossa durante o "inverno" pelo material carreado pela enchente, a tubulação de revestimento foi estendida até ficar com a boca do tubo acima da cota de enchente. Ao redor desse tubo de revestimento foi feito reforço em alvenaria para que o fenômeno sazonal de arraste da água não danificasse a tubulação.

Para elevação da cota da fossa foi especificado que as placas de concreto pré-moldadas ficassem acima da cota de enchente, de maneira que tivesse espaço interno capaz de receber o esgoto do vaso sanitário, e este fosse infiltrando lentamente durante o período de cheia. Por sua vez, para a elevação da cota do piso da instalação sanitária domiciliar (banheiro), foi necessário um conjunto de pilares e laje de concreto armado capaz de manter a estrutura acima do nível máximo da água. Sua cota deve ser superior ao topo da fossa.

As adaptações e sistematização das TS para ambiente de várzea foram, então, normatizadas em 2016 e atualizadas em 2018 por meio da Instrução Operacional Sesan $n^{\circ} 4$ de 4 de julho de 2018 e Instrução Operacional Sesan n 5 de 4 de julho de 2018 (BRASIL, 2018c, 2018d).

Essas foram as principais modificações realizadas para que a implementação da TS pudesse abranger maior diversidade de ambientes e habitat dos moradores da Amazônia. De certo que, em alguns casos, ainda são necessárias adaptações a fim de atender a especificidades locais. Contudo, até o presente momento, percebe-se que o programa Sanear Amazônia conseguiu contemplar grande espectro de público na região.

\section{Considerações Finais}

Os resultados apresentados neste artigo apontam que é possível reverter um cenário de falta de acesso a água e saneamento, por meio da criação e implementação de tecnologias sociais. Além disso o protagonismo das populações extrativistas foi fundamental no processo de criação e desenvolvimento do Projeto Sanear.

Um aspecto emblemático é a resposta que a tecnologia social em questão deu à uma demanda centenária para a população ribeirinha da Amazônia. As TS, elaboradas e construídas a partir de um processo histórico de debates e diálogos entre as comunidades e um corpo técnico, mostraram que a integração de saberes e esforço conjunto pode, sim, ser o remédio sugerido há mais de um século.

De forma geral, percebe-se que, ao longo do tempo de implementação das TS, a definição de seus componentes e o processo para implementação delas ocorreu num processo de retroalimentação entre os diversos atores, envolvendo aspectos técnicos, econômicos, sociais e ambientais. Tal fato implica que essas tecnologias são efetivamente um exemplo de tecnologias sociais que beneficiam as comunidades viabilizando o acesso a um direito humano visando à ampliação da inclusão social e redução da pobreza.

Aqui, deve-se ressaltar o papel fundamental da coordenação técnica de acompanhamento no executor do Projeto Sanear Amazônia, Memorial Chico Mendes (MCM), que no processo de visitas de orientação e vistoria de recebimento das tecnologias, realizado em todas as unida- 
des implantadas, garantiu o diálogo constante entre a comunidade, agentes executores, MCM e Programa Cisternas, promovendo amplo processo de participação social.

O exemplo do Projeto Sanear Amazônia mostra que as organizações da sociedade civil e os movimentos sociais vêm desempenhando um papel estratégico e fundamental na construção de políticas públicas para as comunidades rurais da Amazônia. Efetivamente, é na prática ativa, no protagonismo dos beneficiários e na consolidação dos seus direitos que reside o êxito do Projeto Sanear Amazônia. Ademais, o protagonismo ligado ao Projeto Piloto Sanear promoveu amplo processo de formação de técnicos, lideranças e beneficiários nas reservas extrativistas da Amazônia. Além disso, garantiu as adequações necessárias à política pública de universalização do acesso a água e ao saneamento.

Uma reflexão importante em relação a propostas de tecnologias sociais é que as discussões entre os atores sociais envolvidos ampliem seu escopo de atuação na perspectiva de uma abordagem integrada de acesso ao saneamento rural. Esse é um ponto fundamental no processo de gestão das tecnologias implementadas. Apesar de as tecnologias sociais de acesso ao saneamento rural conferirem autonomia às famílias, é necessário garantir a gestão do sistema para que a qualidade, quantidade e acessibilidade à água sejam mantidas ao longo do tempo. Para isso é necessária a articulação entre beneficiados, arranjos associativos e poder público.

\section{Referências}

BATISTA, D. C. (Org.). Sobre o saneamento da Amazônia. Manaus: Philippe Daou S. A., 1972.

BERNARDES, C. Avaliação integrada de impacto à saúde decorrente de ações de saneamento, em comunidades de unidades de conservação de uso sustentável na Amazônia. 2013. 178 f. Tese (Doutorado em Ciência Ambiental) - Instituto de Energia e Ambiente, Universidade de São Paulo, São Paulo.

BERNARDES, C.; BERNARDES, R. S. Caderno água, saneamento e saúde da população extrativista na Amazônia (Cartilha). Manaus: Memorial Chico Mendes, 2016.

BRASIL. Ministério da Saúde. Portaria n $\mathbf{n}^{\mathbf{2}}$ 2.914, de 12 de dezembro de 2011, que dispõe sobre os procedimentos de controle e de vigilância da qualidade da água para consumo humano e seu padrão de potabilidade. Brasília, DF, 2011. Disponível em: http://www.mpf.mp.br/atuacao-tematica/ccr4/dados-da-atuacao/projetos/qualidade-da-agua/legislacao/portarias/portaria-no-2914-de-12-de-dezembro-de-2011/ view. Acesso em: 01 ago. 2019.

BRASIL. Ministério do Desenvolvimento Social. Instrução Operacional nº 02 de 4 de julho de 2018, que atualiza a especificação do modelo da tecnologia social $n^{\circ} 8$ - Sistema Pluvial Multiuso Autônomo e seu respectivo valor unitário de referência, no âmbito do Programa Cisternas. Brasília, 2018a. Disponível em: http://mds.gov.br/assuntos/seguranca-alimentar/acesso-a-agua-1/marco-legal-1. Acesso em: 01 mar. 2019.

BRASIL. Ministério do Desenvolvimento Social. Instrução Operacional no 03 de 4 de julho de 2018 , que atualiza a especificação do modelo da tecnologia social $n^{\circ} 13$ - Sistema Pluvial Multiuso Comunitário e seu respectivo valor unitário de referência, no âmbito do Programa Cisternas. Brasília, 2018b. Disponível em: http://mds.gov.br/assuntos/seguranca-alimentar/acesso-a-agua-1/marco-legal-1. Acesso em: 01 mar. 2019. 
BRASIL. Ministério do Desenvolvimento Social. Instrução Operacional nº 04 de 4 de julho de 2018, que atualiza a especificação do modelo da tecnologia social $n^{\circ} 12$ - Sistema Pluvial Multiuso Autônomo para ambiente de várzea e seu respectivo valor unitário de referência, no âmbito do Programa Cisternas. Brasília, 2018c. Disponível em http://mds.gov.br/assuntos/seguranca-alimentar/acesso-a-agua-1/marco-legal-1. Acesso em: 01 mar. 2019.

BRASIL. Ministério do Desenvolvimento Social. Instrução Operacional no 05 de 4 de julho de 2018, que atualiza a especificação do modelo da tecnologia social n ${ }^{\circ} 14$ - Sistema Pluvial Multiuso Comunitário para ambiente de várzea e seu respectivo valor unitário de referência, no âmbito do Programa Cisternas. Brasília, 2018d. Disponível em: http://mds.gov.br/assuntos/seguranca-alimentar/acesso-a-agua-1/marco-legal-1. Acesso em: 01 mar. 2019.

CAIRNCROSS, S. R.; FEACHEM, R. G. Environmental health engineering in the tropics: an introductory text. 2. ed. Chichester: John Wiley \& Sons, 1993.

CAMPELlO, T. (Coord.). Faces da desigualdade no Brasil: um olhar sobre os que ficam para trás. Brasília, DF: FLACSO, 2017.

CASTELLANOS, P. L. Sobre el concepto de salud enfermedad. Descripción y explicación de la situación de salud. Boletim Epidemiológico OPS, v. 10, n. 4, p. 1-12, 1990.

DAGNINO, R. Tecnologia social: contribuições conceituais e metodológicas [online]. Campina Grande: EDUEPB, 2014. Disponível em: http://books.scielo.org. Acesso em: 10 dez. 2018.

ESREY, S. A. et al. Effects of improved water supply and sanitation on ascariasis, diarrhoea, dracunculiasis, hookworm infection, schistosomiasis, and trachoma. Bulletin of the World Health Organization, v. 69, n. 5, p. 609-621, 1991.

HOWARD, G.; BARTRAM, J. Domestic water quantity, service and health. Geneva: World Health Organization, 2003.

INSTITUTO BRASILEIRO DE GEOGRAFIA E ESTATÍSTICA - IBGE. Pesquisa Nacional por Amostra de domicílios 2008. Rio de Janeiro, 2008.

JENKINS, M. W.; SCOTT, B. Behavioral indicators of household decision-making and demand for sanitation and potential gains from social marketing in Ghana. Social Science \& Medicine, v. 64, n. 12, p. 2427-2442, 2007.

LASSANCE JUNIOR, A. E.; PEDREIRA, J. S. Tecnologias sociais e políticas públicas. In: LASSANCE JUNIOR, A. E. (Org.). Tecnologia social: uma estratégia para o desenvolvimento. Rio de Janeiro: Fundação Banco do Brasil, 2004. p. 65-81.

OLIVEIRA, K. R. A.; BERNARDES, C. Tecnologias sociais de saneamento na Amazônia: estruturas físicas e capacitação como promotoras de mudanças sociais. In: FÓRUM INTERNACIONAL SOBRE A AMAZÔNIA, 2., 2019, Brasília, DF. [Resumos...]. Brasília, DF: Universidade de Brasília, 2019.

ORGANIZAÇÃO DAS NAÇÕES UNIDAS - ONU. The human right to water and sanitation. Resolution no 64/292, de 28 de julho de 2010. New York: United Nations General Assembly, 2010.

PROGRAMA DAS NAÇÕES UNIDAS PARA O DESENVOLVIMENTO - PNUD. As perguntas mais frequentes sobre os Objetivos de Desenvolvimento Sustentável - ODS (Cartilha). Disponível em: http://www.br.undp.org/content/brazil/pt/home/library/ods/cartilha-de-perguntas-e-respostas-dos-ods. html. Acesso em: 28 fev. 2019. 
WORLD HEALTH ORGANIZATION - WHO. Don't pollute my future! The impact of the environment on children's health. Geneva: World Health Organization, 2017.

WORLD HEALTH ORGANIZATION - WHO. Guidelines for drinking-water quality. 3. ed. Geneve, 2004.

WORLD HEALTH ORGANIZATION - WHO. 6.11 Rainwater harvesting: water quality and health risk. Disponível em: https://www.who.int/water_sanitation_health/gdwqrevision/rainwater.pdf. Acesso em: 01 mar. 2019.

WORLD HEALTH ORGANIZATION - WHO; UNITED NATIONS CHILDREN'S FUND - UNICEF. Progress on drinking water: 2017 update and SDG Baselines. Geneva, 2017. Disponível em: http://apps. who.int/iris. Acesso em: 10 dez. 2018. 